Mihály Csótó

\title{
E-GOVERNMENT SERVICE ADOPTION THROUGH THE LENS OF THE KNOWLEDGE GAP
}

Mihály Csótó, Managing Director, Chelonian Bt., csoto.mihaly@gmail.com

The aim of the paper is to raise some issues in relation to the technology adoption-based e-government acceptance models and that the knowledge gap theory can be applied to the use of online public administration services: higher status equals not only wider and more sophisticated usage of ICT tools, but also more knowledge about public administration procedures themselves, which can result in various channel-preferences and routines among the users of different public services. Using data from the multivariable Good State Public Administration Opinion Survey, the paper shows that the knowledge gap clearly exists in terms of public administration-related knowledge. Based on this finding, the paper recommends that the currently marginally used 'necessary knowledge about public administration procedures' factor should be more widely incorporated in e-government adoption models, as it can have a significant effect on adoption, or alter the effect of other constructs in these models.

KEYWORDS:

e-government, trust in internet, digital divide, public administration-related knowledge, public service channel-preferences 


\section{INTRODUCTION}

Researchers have studied the factors that influence citizen adoption of e-government in various countries for decades. Gupta, Singh, and Bashkar state in their short review of the term 'adoption of e-government' that the central element of the term is the intention or willingness to use e-government services. ${ }^{1}$ The line of research using this approach mainly focused on governmental websites/services for information provision and digital transactions as information technology systems and consider 'e-government' a more or less homogenous service and concept. However, Kumar et al. claimed that e-government adoption is multidimensional: it contains the frequency of usage (one-time vs. regular usage), the scope of usage (one type of service vs. many services, information provision vs. transaction) and most importantly, 'preference of the online medium over other mediums of transactions with government'. ${ }^{2}$ Dealing with public administration requires knowledge about various procedures, not only computer systems (for example, cases might require authentication, payment and specific documents). Based on the theory of the knowledge gap, this paper reviews the main constructs and models from e-government adoption literature and argues that to reach higher levels of digital service take-up based on the help of currently used models, more fine tuning in public administration-specific models may be required.

\section{THE RICH RESEARCH FIELD OF ADOPTION OF E-GOVERNMENT SERVICES AS A TECHNOLOGY}

The adoption of different e-government services is one of the focal points of the rapidly expanding scientific literature on e-government. Van Dijk et al. gave a good summary of the relevant theoretical frameworks that have been widely used in recent decades to describe and understand the proliferation of e-services (or even the lack thereof) in the early stages of e-government development: ${ }^{3}$

- The Theory of Diffusion of Innovations (DOI) ${ }^{4}$

- Technology Acceptance Model (TAM) ${ }^{5}$

1 Kriti Priya Gupta, Swati Singh and Preeti Bhaskar, 'Citizen adoption of e-government: a literature review and conceptual framework', Electronic Government, An International Journal 12, no 2 (2012), 160-185.

2 Vinod Kumar, Bhasker Mukerji, Irfan Butt and Ajax Persaud, 'Factors for successful e-government adoption: a conceptual framework', Electronic Journal of E-Government 5, no 1 (2007), 63-76.

3 Jan AGM Van Dijk, Oscar Peters and Wolfgang Ebbers, 'Explaining the acceptance and use of government Internet services: A multivariate analysis of 2006 survey data in the Netherlands', Government Information Quarterly 25, no 3 (2008), 379-399.

Everett M Rogers, Diffusion of Innovations ( $5^{\text {th }}$ edition) (New York: Free Press, 2003).

5 Fred D Davis, 'Perceived Usefulness, Perceived Ease of Use, and User Acceptance of Information Technology', MIS Quarterly 13, no 3 (1989), 319-340. 
- Social Learning Theory ${ }^{67}$

- The Theory of Technology Domestication ${ }^{8}$

- The Theory of Reasoned Action (TRA), ${ }^{9}$ or the Theory of Planned Behaviour (TPB) ${ }^{10}$

As Aranyossy put it, in the past decade the use of the UTAUT model (Unified Theory of Acceptance and Use of Technology) gained acceptance in e-government literature; ${ }^{11}$ however, the TAM and the DOI are also still popular among researchers who seek to construct technology acceptance models. ${ }^{12}$ Rana, Dwivedi and Williams compared the various IS/IT adoption research models being used in e-government adoption. Their findings indicated that TAM was used the most frequently, followed by DOI (in a somewhat reduced way, as the constructs compatibility, complexity and relative advantage were mainly in use across various studies), and also all the constructs of the UTAUT model (except facilitating conditions), were used quite regularly. ${ }^{13}$

The UTAUT model was developed by Venkatesh et al., with the integration of eight other models (the already mentioned TRA, TAM, TPB, DOI and Combined TAM-TPB, the Motivational Model [MM], the Model of PC Utilisation [MPCU] and the Social Cognitive Theory $[\mathrm{SCT}]) .{ }^{14}$ The UTAUT amalgamates earlier constructs to form a comprehensive model that 'appeared to be significant direct determinants of intention or usage in one or more of the individual models'. The model includes four predictors: performance expectancy (PE, defined as the degree to which an individual believes that using the system will help him or her to improve in job performance), effort expectancy (EE, defined as the degree

6 Albert Bandura, Social Foundations of Thought and Action: A Social Cognitive Theory (Englewood Cliffs NJ: Prentice-Hall, 1986).

7 Robert Larose, Dana Mastro and Matthew S Eastin, 'Understanding Internet Usage: A social cognitive approach to uses and gratifications', Social Science Computer Review 19, no 4 (2001), 395-413.

8 Roger Silverstone and Leslie Haddon, 'Design and the domestication of information and communication technologies: Technical change and everyday life', in Communication by design: The politics of information and communication technologies, ed. by Roger Silverstone and Robin Mansell (Oxford: Oxford University Press 1996).

9 Martin Fishbein and Icek Ajzen, Beliefs, Attitude, Intention and Behavior: An Introduction to Theory and Research (Reading, MA: Addison-Wesley, 1975).

10 Icek Ajzen, 'From Intentions to Actions: A Theory of Planned Behavior', in Action Control: From Cognition to Behavior, ed. by Julius Kühl and Jürgen Beckmann (Berlin-Heidelberg: Springer, 1985).

11 Márta Aranyossy, 'Citizen adoption of e-government services: Evidence from Hungary', in $31^{\text {st }}$ Bled eConference Digital Transformation: Meeting the Challenges: 17-20 June 2018, Bled, Slovenia, Conference Proceedings, ed. by Adreja Pucihar, Mirjana Kljajić Borštnar, Pascal Ravesteijn, Jurgen Seitz and Roger Bons (Maribor: University of Maribor Press, 2018), 27-46.

12 For a summary of e-government adoption research using different technology acceptance models or the main constructs from them, see for example Gupta et al., 'Citizen adoption of e-government', or Khaled Ahmed Al Mansoori, Use of a Modified UTAUT Model to Investigate Emirati Citizens' Adoption of e-Government in Abu Dhabi (PhD Thesis, University of Wollogong MBA, Faculty of Business, 2007).

13 Nripendra P Rana, Yogesh K Dwivedi and Michael D Williams, 'Evaluating alternative theoretical models for examining citizen centric adoption of e-government', Transforming Government: People, Process and Policy 7 , no 1 (2013), 27-49.

14 Viswanath Venkatesh, Michael G Morris, Gordon B Davis and Fred D Davis, 'User Acceptance of Information Technology: Toward a Unified View', MIS Quarterly 27, no 3 (2003), 425-478. 
of ease associated with the use of the system), social influence (SI, defined as the degree to which an individual perceives that people of importance believe he or she should use the new system), and facilitating conditions (FC, defined as the degree to which an individual believes that an organisational and technical infrastructure exists to support the use of the system). As Figure 1 shows, the model also contains two outcomes (Behavioural Intention [BI] and Use Behaviour [UB]) and four moderator variables (gender, age, experience and voluntariness of use).

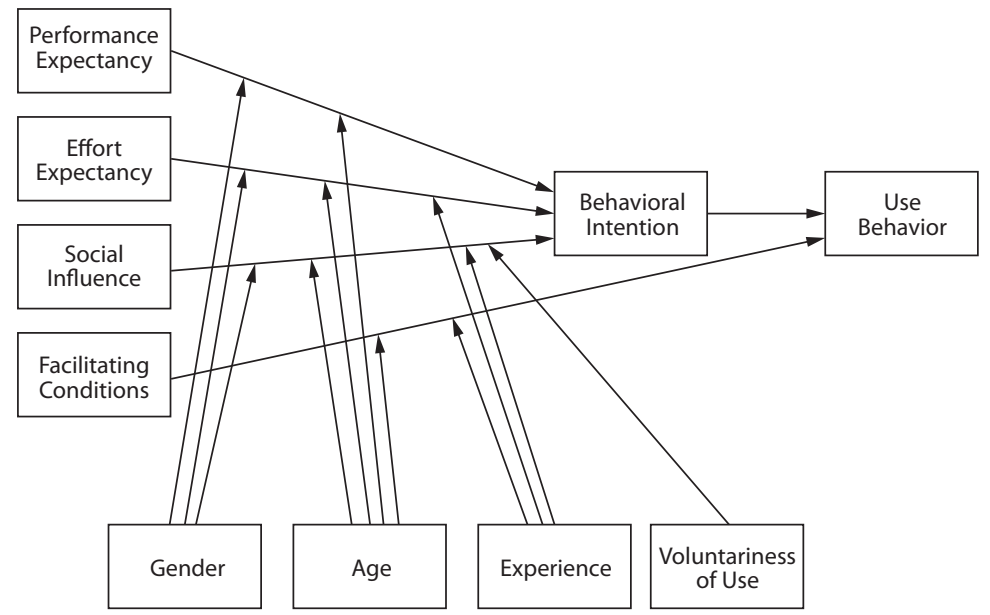

Figure 1 - The UTAUT research model (Source: Venkatesh et al. 2003.)

Numerous studies have used this model or a modified version of it in the context of e-government (also in Eastern Europe ${ }^{1516}$ ); however, as Venkatesh et al. noted, UTAUT was developed to understand behavioural intention to use a technology and technology usage primarily in organisational context, primarily by employees. ${ }^{17}$ The UTAUT model has been extended to new contexts, with e-government adoption being one of them. Tailoring UTAUT to the e-government context necessitated certain modifications so that some original items were (partially) rephrased and/or new items were added. The items in the constructs often used or proposed by various studies are usually general statements related narrowly to computer-related activities (for example, PE: this government website... ...increases my efficiency, ... is useful for me, ...enables me to accomplish task more quickly,

15 Anastasia Voutinioti, 'Determinants of User Adoption of e-Government Services in Greece and the role of Citizen Service Centres', Procedia Technology 8 (2013), 238-244.

16 Edin Osmanbegović and Zijad Lugavić, 'Influencing factors of e-government services adoption in Bosnia and Herzegovina', Economic Review - Journal of Economics and Business 16, no 2 (2018), 39-51.

17 Viswanath Venkatesh, James Y L Thong and Xin Xu, 'Consumer acceptance and use of information technology: extending the unified theory of acceptance and use of technology', MIS Quarterly 36, no 1 (2012), 157-178. 
using E-Government services would increase my overall productivity; EE: ...is clear and understandable, is easy to use, ...is flexible, ...is complicated; FC: I have the resources necessary to use e-Government services, e-Government services are compatible with other technologies I use, the necessary assistance is available for using this e-government website), but at times the specific nature of e-government can be traced in items which suggests that interaction with public administration takes place mainly face-to-face (or in limited cases by telephone, or post) or online (PE: I think interacting with the government face to face would be preferable to interacting online; EE: I would find it easier to talk face to face with someone rather than use online services; FC: the necessary assistance for using the e-government website is available at CSCs [Citizen Service Centres]). There are statements that go far beyond technology or the understanding of technology (PE: my interaction with e-Government services would be clear and understandable; FC: I have the knowledge necessary to use e-Government services, I would not like to carry out my business with government online), into the realm of habits or more general knowledge (item examples are from the research of Alawadhi and Morris, ${ }^{18}$ Voutinioti $^{19}$ and Al Mansoori ${ }^{20}$ ). One may question whether these constructs are perfectly applicable to the context of public administration, and retain the validity of the original model.

The UTAUT2 model (building on the past extensions to UTAUT) paid particular attention to consumer use context rather than organisational focus, but e-government does not occur as a consumer experience in the strictest sense of the word. Therefore, two out of the three new constructs incorporated in the model (hedonic motivation and price value) are difficult to implement in this domain. Hedonic motivation is about deriving pleasure from using a system, and there can be little doubt that few citizens use e-government systems for their pleasure. Price-value is about the trade-offs between costs and benefits associated with usage of the technology, but in most public administration processes, the price is the same for every channel, or the costs associated with face-to-face encounters (for example, traveling time) are hard to measure. (However, examples and initiatives can be found for financial incentives to encourage citizens to use public services through the internet.) Much previous research using UTAUT2 to examine e-government adoption does not consider these factors. ${ }^{21}$ Habit was also added to UTAUT. The construct is treated as a self-reported perception about the level of automation involved in a task, and can be also complicated to adapt in the context of e-government (as the original construct is consisted

18 Suha AlAwadhi and Anne Morris, 'The Use of the UTAUT Model in the Adoption of E-Government Services in Kuwait', in Proceedings of the 41 st Annual Hawaii International Conference on System Sciences (HICSS 2008), 219-219.

19 Anastasia Voutinioti, 'Determinants of User Adoption of e-Government Services in Greece and the role of Citizen Service Centres'.

20 Al Mansoori, Use of a Modified UTAUT Model.

21 Aranyossy, 'Citizen adoption of e-government services: Evidence from Hungary'; Nemer Aburumman and Róbert Szilágyi, 'Factors Affecting Acceptance of Government: Using Extended UTAUT2', Journal of EcoAgriTourism 16, no 1 (2020), 62-69. 
of three items: mobile internet is has become a habit for me, I am addicted to using mobile internet, I must use mobile internet).

Attempts have also been made to define e-government-specific models instead of extending or modifying existing ones. Shareef et al. developed an e-government specific adoption model (Figure 2) because in their opinion, TAM, DOI, TPB cannot capture and specify the complete essence of the e-Gov adoption behaviour of private individuals (however, the model is a good summary of the relevant factors from all the models mentioned earlier, but rephrased and extended with some domain-specific factors). ${ }^{22}$ The e-Government Adoption Model (GAM) also takes into account service maturity levels, which is an important distinction: the authors concluded that the e-government adoption behaviour also differs based on service maturity levels, which means the acceptance of services have to be analysed in a dynamic environment, where the functional characteristics of organisational, technological, economic and social perspectives of e-government differ. In other words, adoption of different services is affected by their maturity (and supposedly their complexity).

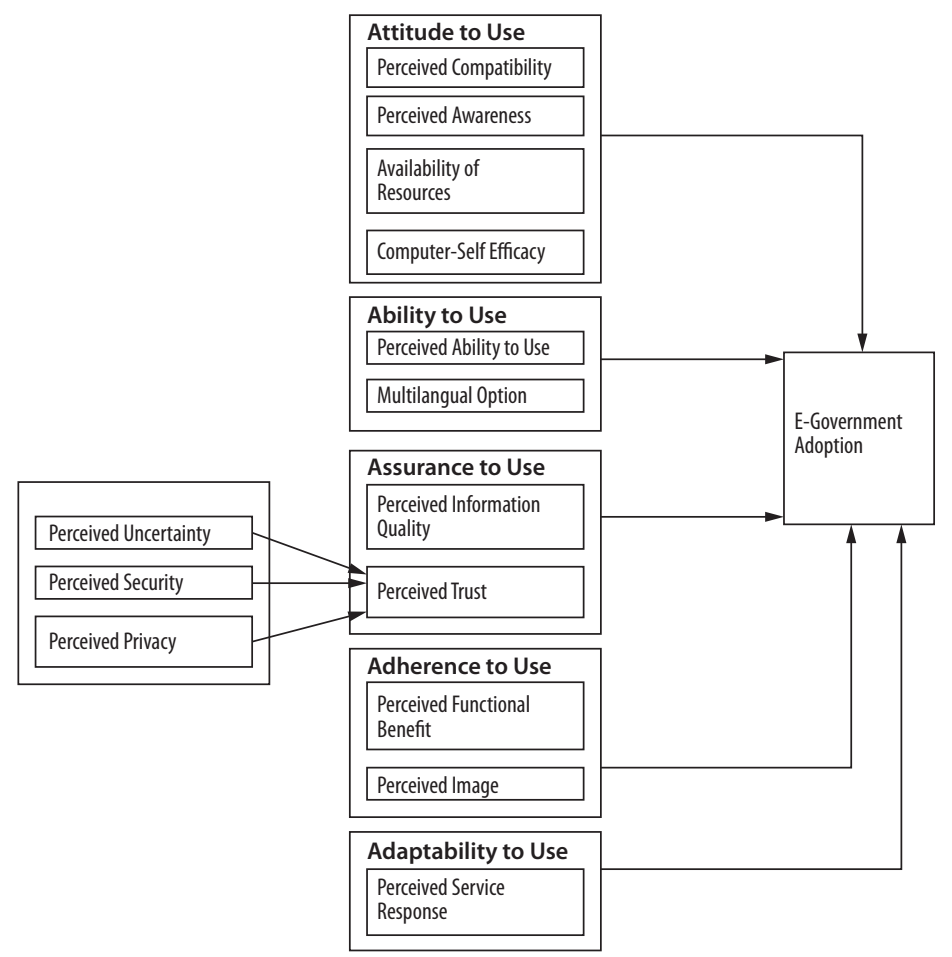

Figure 2 • The e-Government Adoption Model (Source: Shareef et al. 2011.)

22 Mahmud Akhter Shareef, Vinod Kumar, Uma Kumar and Yogesh Dwivedi, 'E-Government adoption model (GAM): differing service maturity levels', Government Information Quarterly 28, no 1 (2011), 17-35. 
If we take a closer look at the constructs, one additional and important element which can be seen is trust. The presence of trust is not surprising. In the literature dealing with e-government take up, almost every specific model contains, adds or develops some kind of trust-related construct, which is regarded as a separate dimension in most, ${ }^{23}$ although trust is defined and measured in various ways (for example, trust of the government, trust of the internet, trust of the system, trust of authentication, privacy issues, and so on). Early research by Wang examined factors affecting the proliferation of an electronic tax return system in Taiwan. ${ }^{24}$ The research was based on the TAM model, but expanded it with a 'perceived credibility' dimension. The general tendency is to incorporate different constructions of trust into the explanatory variables in the use of acceptance models. Lean et al. ${ }^{25}$ tested a model based on the work of Carter and Bélanger ${ }^{26}$ and Suh and Han. ${ }^{27}$ The study integrates constructs from TAM and DOI which have been moderated by a culture variable (uncertainty avoidance) and a trust model in five dimensions (Figure 3). Belanche, Casaló and Flavián also proposed to integrate trust and personal values into the Technology Acceptance Model. ${ }^{28}$

Individual, personal characteristics have always been an important part of acceptance models, although there are only a few studies that look beyond constructs related to technology (which is not surprising in the end as the purpose of the used models is to explain technology acceptance). Nevertheless, other, more public administration-related factors may affect the various technology adoption measures. There are only a few constructs which appear in different related models about this topic. As can be seen in Figure 3, Lean et al. placed uncertainty avoidance in the model, which attempted to show discomfort related to complicated administrative matters and fear of possible errors and sanctions (even if its effect was not significant in their case). ${ }^{29}$ However, similar constructs have been considered in UTAUT, such as self-efficacy, anxiety and attitude, but these were dropped from the model after the first iteration. ${ }^{30}$ However, we can argue that there are differences between adopting job-related IT in an organisation and adopting e-government.

23 For example Aranyossy, 'Citizen adoption of e-government services: Evidence from Hungary’; Aburumman and Szilágyi, 'Factors Affecting Acceptance of Government: Using Extended UTAUT2', or Voutinioti, 'Determinants of User Adoption of e-Government Services in Greece and the role of Citizen Service Centres'.

24 Yi-Shun Wang, 'The adoption of electronic tax filing systems: an empirical study', Government Information Quarterly 20, no 4 (2003), 333-352.

25 Ooh Kim Lean, Suhaiza Zailani, T Ramayah and Yudi Fernando, 'Factors influencing intention to use e-government services among citizens in Malaysia', International Journal of Information Management 29, no 6 (2009), 458-475.

26 Lemuria Carter and France Belanger, 'The utilization of e-government services: Citizen trust, innovation and acceptance factors', Information Systems Journal 15, no 1 (2005), 5-25.

27 Bomil Suh and Ingoo Han, 'The impact of customer trust and perception of security control on the acceptance of electronic commerce', International Journal of Electronic Commerce 7, no 3 (2003), 135-161.

28 Daniel Belanche, Luis V Casaló and Carlos Flavián, 'Integrating trust and personal values into the Technology Acceptance Model: The case of e-government services adoption', Cuadernos de Economía y Dirección de la Empresa 15, no 4 (2012), 192-204.

29 Lean et al., 'Factors influencing intention to use e-government services among citizens in Malaysia'.

30 Venkatesh et al., 'User Acceptance of Information Technology: Toward a Unified View'. 


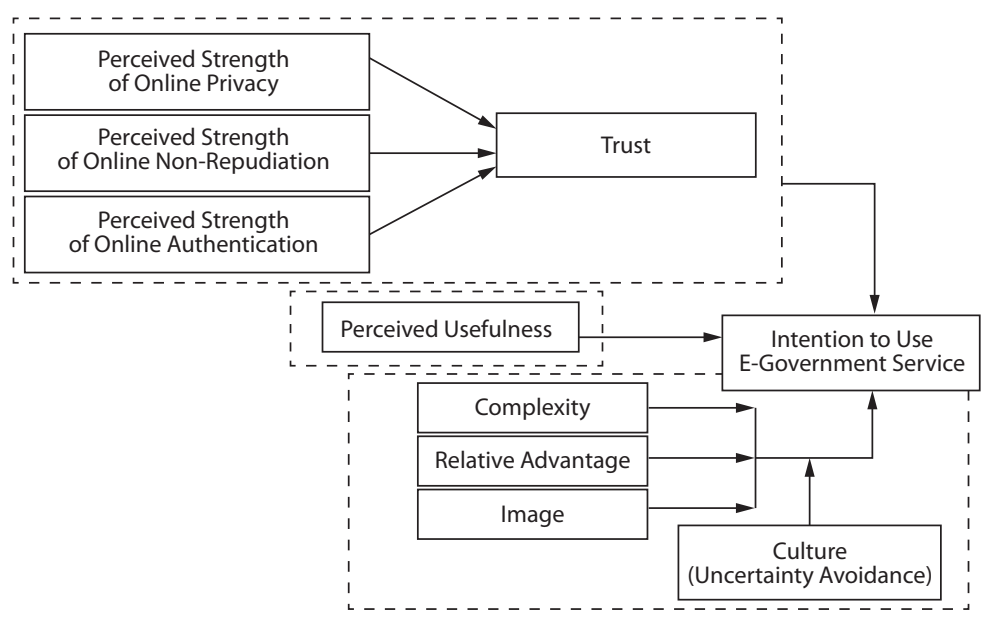

Figure 3 - Theoretical framework used by Lean et al. (Source: Lean et al. 2009.)

Seo and Bernsen were among the few who implemented the knowledge of public administration procedures as an enabling factor while they investigated the attitudes of non-users versus users toward e-government services in two locales. Starting from the original definition of self-efficacy, their hypothesis was that people prefer traditional, over-the-counter government services if they are unfamiliar with and insecure about certain procedures (because they do not understand the procedure, the terms used in the documents, and so on) as in that way they can gain support and guidance through the process. The basic knowledge about procedures can empower people to perform relevant tasks. Seo and Bernsen create the factor 'perceived necessary knowledge' ${ }^{31}$ and define it as 'the knowledge one perceives to be required in understanding related terms and following a given procedure.' ${ }^{2}$ The construct is a determinant of 'perceived behavioural control' by Ajzen ${ }^{33}$ and, as Seo and Bernsen put it, it is important to include factors beyond perceived usefulness and perceived ease of use, because a person is not without limitation (s)he forms an intention to act: limited capabilities, time or environmental resources can limit the freedom or ability to act (and the self-efficacy factor can be seen as being an antecedent of perceived behavioural control). The research conducted by Dimitrova and Chen among American internet users has shown a strong relationship with the experience and technical skills of internet use and the use of e-government, and also show that personal

31 The construct of perceived necessary knowledge contained three items: 'I had (expect to have) the knowledge necessary to follow the procedures of municipality eServices', 'I had (expect to have) the knowledge to interact through municipality eServices', 'I had (expect to have) the knowledge necessary to understand the underlying procedures and mentioned terminology in the municipality eServices'.

32 DongBack Seo and Michel Bernsen, 'Comparing attitudes toward e-government of non-users versus users in a rural and urban municipality', Government Information Quarterly 33, no 2 (2016), 270-282.

33 Icek Ajzen, 'The theory of planned behaviour', Organizational Behavior and Human Decision Processes 50, no 2 (1991), 179-211. 
attitudes toward uncertainty affect adoption. ${ }^{34}$ Familiarity with processes ('Prior interest in government', measured by earlier contacts with government officials in the past) was also a significant factor. This leads us to the knowledge gap theory which can contribute to formulating a more precise model of e-government service adoption.

\section{KNOWLEDGE GAP THEORY - IS IT VALID FOR KNOWLEDGE ABOUT PUBLIC ADMINISTRATION ISSUES?}

The core statement of the knowledge gap theory is that there is a discrepancy in people's level of knowledge about issues (or as Wexler has recently stated, knowledge about the world ${ }^{35}$ ), which varies according to their socioeconomic status (SES) and it is caused by the different ways of engagement with mass media content. The theory was formulated in the early 1970s by Tichenor, Donohue and Olien: 'As the infusion of mass media information into a social system increases, higher socioeconomic status segments tend to acquire this information faster than lower socioeconomic-status population segments so that the gap in knowledge between the two tends to increase rather than decrease.' The theory also gave five reasons why the knowledge gap exists: 1. communication skills (more education improves reading and memory skills); 2. stored information/prior, already existing knowledge; 3. relevant social contact (higher status people have more diverse social connections); 4 . personal media reference (lower status people may be looking for less domains in the media); 5. resource structure (certain sources are targeted for their specific audiences). ${ }^{36}$ Natalia Wrexler's latest book ("The Knowledge Gap" ${ }^{37}$ ) is somehow rebuilding the concept, examining the root causes behind it, through the example of the education system in the USA.

Two narrative reviews of knowledge gap-related literature, Gaziano ${ }^{38}$ and a meta-analysis of 46 knowledge gap studies, ${ }^{39}$ proves the existence of a knowledge gap. The analysis carried out by Hwang and Jeong also shows that the magnitude of this SES-knowledge relationship varies across different studies ranging from relatively weak to relatively strong, and moderated by the topic of knowledge. The review found that in case of the knowledge of social-political issues, the knowledge gap is wider in comparison to other topics (for

34 Daniela V Dimitrova and Yu-Che Chen, 'Profiling the Adopters of E-Government Information and Services: The Influence of Psychological Characteristics, Civic Mindedness, and Information Channels', Social Science Computer Review 24, no 2 (2006), 172-188.

35 Natalie Wexler, The Knowledge Gap (New York: Avery, 2019).

36 Phillip J Tichenor, George A Donohue and Clarice N Olien, 'Mass media flow and differential growth in knowledge', Public Opinion Quarterly 34, no 2 (1970), 159-170.

37 Wexler, The Knowledge Gap.

38 Cecilie Gaziano, 'The knowledge gap: An analytical review of media effects', Communication Research 10, no 4 (1983), 447-486; Cecilie Gaziano, 'Forecast 2000: Widening knowledge gaps', Journalism \& Mass Communication Quarterly 74, no 2 (1997), 237-264.

39 Yoori Hwang and Se-Hoon Jeong, 'Revisiting the knowledge gap hypothesis: A meta-analysis of thirty-five years of research', Journalism \& Mass Communication Quarterly 86, no 3 (2009), 513-532. 
example, health and science knowledge). Social-political issues are not the same as public administration issues, but it can be stated that the latter may also be counted under the domains that are more difficult to grasp and therefore where the knowledge gap may be more obvious.

Bonfadelli examined the knowledge gap theory in the internet era and found that the internet may have a direct or indirect impact on every member of society as a whole, but those with a higher status also use it more quickly and efficiently, and states that the knowledge gaps in digital media use may be more extreme than gaps in the uses of traditional mass media. ${ }^{40}$ It can also be observed in the so-called 'second-level digital divides', which refers to the gaps in usage skills that can persist after the divides of physical internet access have been overcome. ${ }^{41}$ Hargittai and Hsieh state that digital inequality can refer both to how existing social inequalities can affect the adoption and use of digital technologies, but also how differential uses of the Internet can influence social stratification. ${ }^{42}$ While Hwang and Jeong found that there were no significant differences in the magnitude of the knowledge gap between the two time points in classical knowledge gap studies, this may change with the proliferation of interactive, digital media. ${ }^{43}$

As demonstrated in the literature above, the examination of knowledge gaps in e-government service adoption can contribute to the comprehensive understanding of the phenomenon, and offers a wider context and provides the opportunity to fine-tune e-government adoption models. In order to do so, it is important to make the case that a knowledge gap exists among the public with regards to public administration knowledge.

\section{METHODOLOGY}

The empirical basis of the research is the Good State Public Administration Opinion Survey (GSPAOS), which was carried out in Hungary in the middle of 2017 by Szociometrum Social Science Research. The survey questions were tested on a representative sample of the adult (age 18+) Hungarian population. The sampling method was multistage, proportionally stratified probability sampling, while the database was also corrected ex post with matrix weighting procedure in respect to age, gender, region, settlement type and education. The survey contained 70 questions, some with many sub-questions, to explore many aspects of public opinion on public administration including the digitalisation of different procedures. Among others, the survey provided the opportunity to use a large $(n=2506)$

40 Heinz Bonfadelli, 'The Internet and Knowledge Gaps: A Theoretical and Empirical Investigation', European Journal of Communication 17, no 1 (2002), 65-84.

${ }_{41}$ Eszter Hargittai, 'Second-level digital divide: differences in people's online skills', First Monday 7, no 4 (2002).

42 Eszter Hargittai and Yuli P Hsieh, 'Digital Inequality', in The Oxford Handbook of Internet Studies, ed. by William H Dutton (Oxford: Oxford University Press, 2013), 129-150.

43 Hwang and Jeong, 'Revisiting the knowledge gap hypothesis: A meta-analysis of thirty-five years of research'. 
representative database, with data about citizens' usage and experience of different areas of e-government services, their channel preferences and the obstacles they face while dealing with public administration procedures.

During the construction of the questionnaire for the survey (as the first of its kind), there was no intention to build or test any adoption models; however, many constructs that were presented earlier in the literature section of this paper can be examined. For this paper, three main constructs were built using the items from the questionnaire: trust in the internet (using questions relating to the intention of giving personal/financial data on the internet), the difficulty of dealing with public administration (containing items relating to perceived difficulties with communicating and with filling out forms, which can also be treated as subscales) and intensity and variety of internet use. As Hwang and Jeong put it, the measurement of knowledge (belief-type, awareness-type, factual-type) was also found to be a significant moderator of the knowledge gap in various studies. ${ }^{44}$ The difficulty of dealing with public administration constructs is based on perceived capabilities and therefore, of a less factual-type. In that way the results may show a narrower gap. The original questions/items and the reliability of the scales (Cronbach's Alpha) are included in Table 1. The questions were measured on a Likert scale and were used for factor analysis to calculate the constructs (as they can be viewed as an interval scale ${ }^{45}$ ).

Table 1 - The questions/items and answer options used for the constructs of this study (Source: Good State Public Administration Opinion Survey 2017.)

\begin{tabular}{|c|c|}
\hline $\begin{array}{l}\text { Trust in the Internet, privacy } \\
\text { (Cronbach's Alpha: 0.849) }\end{array}$ & Answer option \\
\hline I never give my bank account data while shopping online. & $1-$ perfectly true .... 4 - not true at all \\
\hline I do not register on online platforms unless I have to. & 1 - perfectly true .... 4 - not true at all \\
\hline I am averse to giving my personal information on the Internet. & $1-$ perfectly true .... 4 - not true at all \\
\hline $\begin{array}{l}\text { There are some personal data of mine that I would not give even } \\
\text { while registering on state organisations' websites. }\end{array}$ & 1 - perfectly true .... 4 - not true at all \\
\hline $\begin{array}{l}\text { Difficulty of dealing with public administration } \\
\text { (Cronbach's Alpha: 0.918) }\end{array}$ & \\
\hline Official communication (Cronbach's Alpha: 0.895) & \\
\hline $\begin{array}{l}\text { How difficult is for you when conducting a formal/official } \\
\text { telephone conversation? }\end{array}$ & $\begin{array}{l}1 \text { - I am unable to do it .... } 4 \text { - I am } \\
\text { easily capable of doing it }\end{array}$ \\
\hline How difficult is for you to write an official letter? & $\begin{array}{l}1 \text { - I am unable to do it .... } 4 \text { - I am } \\
\text { easily capable of doing it }\end{array}$ \\
\hline $\begin{array}{l}\text { How difficult is for you to articulate your case in person with } \\
\text { customer services? }\end{array}$ & $\begin{array}{l}1 \text { - I am unable to do it .... } 4 \text { - I am } \\
\text { easily capable of doing it }\end{array}$ \\
\hline
\end{tabular}

44 Hwang and Jeong, 'Revisiting the knowledge gap hypothesis: A meta-analysis of thirty-five years of research'.

45 James Carifio and Rocco J Perla, 'Ten common misunderstandings, misconceptions, persistent myths and urban legends about Likert scales and Likert response formats and their antidotes, Journal of Social Sciences 3 , no 3 (2007), 106-116. 


\begin{tabular}{|c|c|}
\hline How difficult is for you to prepare a power of attorney? & $\begin{array}{l}1 \text { - I am unable to do it .... } 4 \text { - I am } \\
\text { easily capable of doing it }\end{array}$ \\
\hline How difficult is it for you to commission a lawyer? & $\begin{array}{l}1 \text { - I am unable to do it .... } 4 \text { - I am } \\
\text { easily capable of doing it }\end{array}$ \\
\hline \multicolumn{2}{|l|}{ Filling out forms (Cronbach's Alpha: 0.889) } \\
\hline $\begin{array}{l}\text { It is characteristic of me that I have difficulties in filling out official } \\
\text { forms. }\end{array}$ & $1-$ perfectly true .... 4 - not true at all \\
\hline $\begin{array}{l}\text { It is characteristic of me that I have difficulties in understanding } \\
\text { official forms. }\end{array}$ & $1-$ perfectly true .... 4 - not true at all \\
\hline $\begin{array}{l}\text { It is characteristic of me that I have difficulties in filling out the } \\
\text { necessary data in official forms. }\end{array}$ & 1 - perfectly true .... 4 - not true at all \\
\hline $\begin{array}{l}\text { It is characteristic of me that I have difficulties if I have to justify } \\
\text { the data filled in official forms. }\end{array}$ & $1-$ perfectly true .... 4 - not true at all \\
\hline $\begin{array}{l}\text { It is characteristic of me that I usually ask for help in filling out } \\
\text { official forms. }\end{array}$ & $1-$ perfectly true .... 4 - not true at all \\
\hline \multicolumn{2}{|l|}{$\begin{array}{l}\text { Intensity and variety of internet use } \\
\text { (Cronbach's Alpha: } \mathbf{0 . 8 0 2} \text { ) }\end{array}$} \\
\hline \multicolumn{2}{|l|}{ How often do you carry out the following activities? } \\
\hline searching online & 1 - never .... 4-almost every day \\
\hline reading news online & 1 - never .... 4 - almost every day \\
\hline e-mail & 1 - never .... 4 - almost every day \\
\hline online messaging & 1 - never .... 4-almost every day \\
\hline using social media sites & $1-$ never .... 4 - almost every day \\
\hline VOIP & 1 - never .... 4 - almost every day \\
\hline learning activities online & 1 - never .... 4 -almost every day \\
\hline shopping online & 1 - never .... 4-almost every day \\
\hline selling online & 1 - never .... 4-almost every day \\
\hline online banking & 1 - never .... 4-almost every day \\
\hline managing public utilities & 1 - never .... 4-almost every day \\
\hline
\end{tabular}

\section{RESULTS - WHERE IS THE KNOWLEDGE GAP?}

Our hypothesis is that the existence of the knowledge gap can be observed not only in the usage patterns of the internet, but also in the perceived capability to deal with public administration procedures (as a construct for examining public administrationrelated knowledge). Both constructs were calculated in two ways in order to give a deeper understanding: for public administration knowledge, two subscales were also created (communicating with public administration, managing official forms), and the variety and intensity of internet use were further divided into basic, communicational and transactional factors (these distinctions can also be seen in Table 1, with different background colour). To prove the existence of the knowledge gap, we examined our constructs against education, as the main predictor of socioeconomic status (Figure 4 and 5). 
The literature dealing with the secondary digital divide states that education significantly affects internet usage habits, and this finding can be clearly seen in the results (Figure 4). There are huge discrepancies between people who have or have not at least completed secondary level education (among all internet users in the sample), and people with higher education can make the most out of the internet.

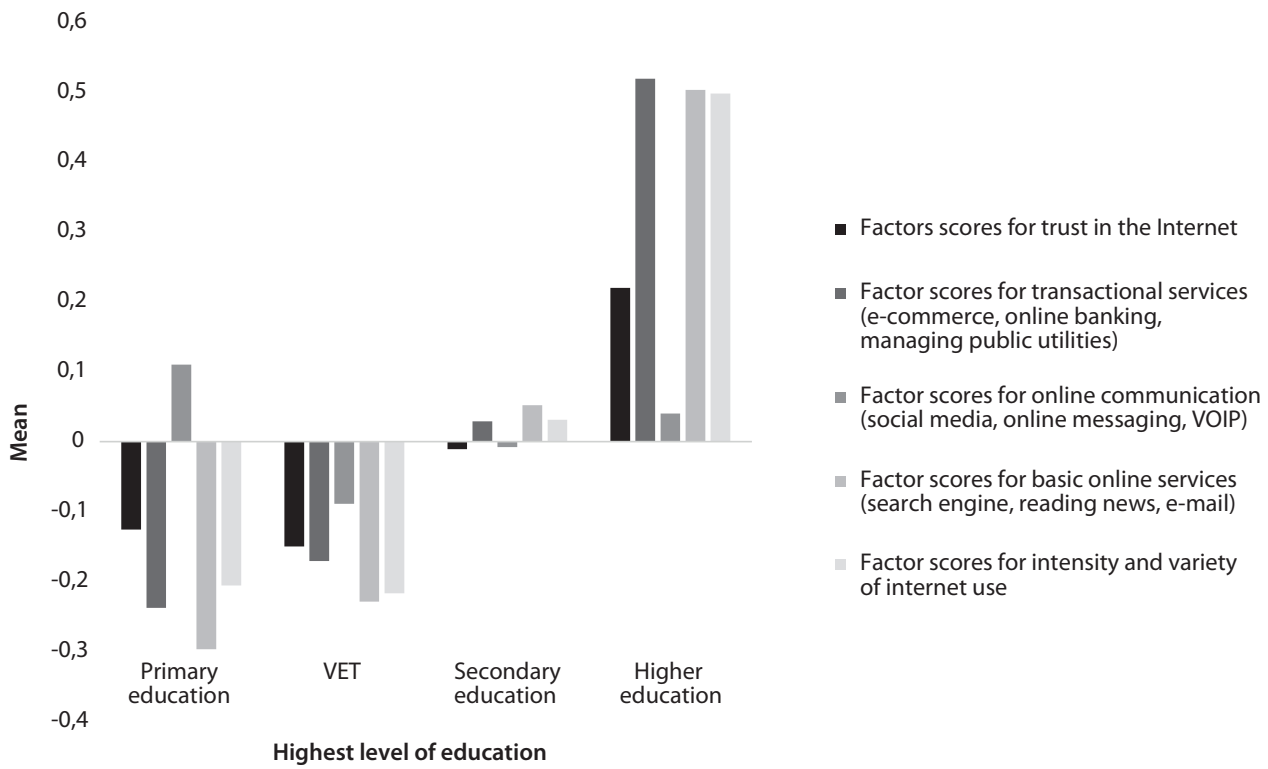

Figure 4 - Trust in the internet and the intensity and variety of internet use (in three categories and summarised) between educational groups, $N=1651$ (Source: Good State Public Administration Opinion Survey 2017.)

One important and unexpected thing is that people with only a primary education use social sites and other forms of online communication rather actively (while not pursuing any other activities on the internet frequently). It may provide an opportunity to target customer service to a customer base that is hard to achieve with digital means of communication. Trust in the internet is showing the same patterns and moving together with the variety and intensity of internet use (this is partially caused by experience with transactional services in general). It shows that computer self-efficacy, a major factor in almost every e-government adoption model, is also deeply rooted in socioeconomic factors.

This finding is also in line with the models which incorporate education as a moderating factor, strongly mediating information technology-related usage - but this is also true in terms of public administration knowledge/capabilities. The only difference is that a smoother, cascading transition can be observed (Figure 5) between the educational group. The more educated someone is, the less difficulties (s)he has while communicating with public administration or managing/filling out forms (there is no major distinction 
between communication and transactions, if somebody finds discomfort in dealing with public administration, it is mainly about the whole experience). Therefore, people who are less educated require more aid in dealing with their public service-related issues, as they find filling out forms and communicating with officials much more difficult. We can state that the knowledge gap clearly (and significantly) exists with regard to public administrationrelated knowledge.

0,9

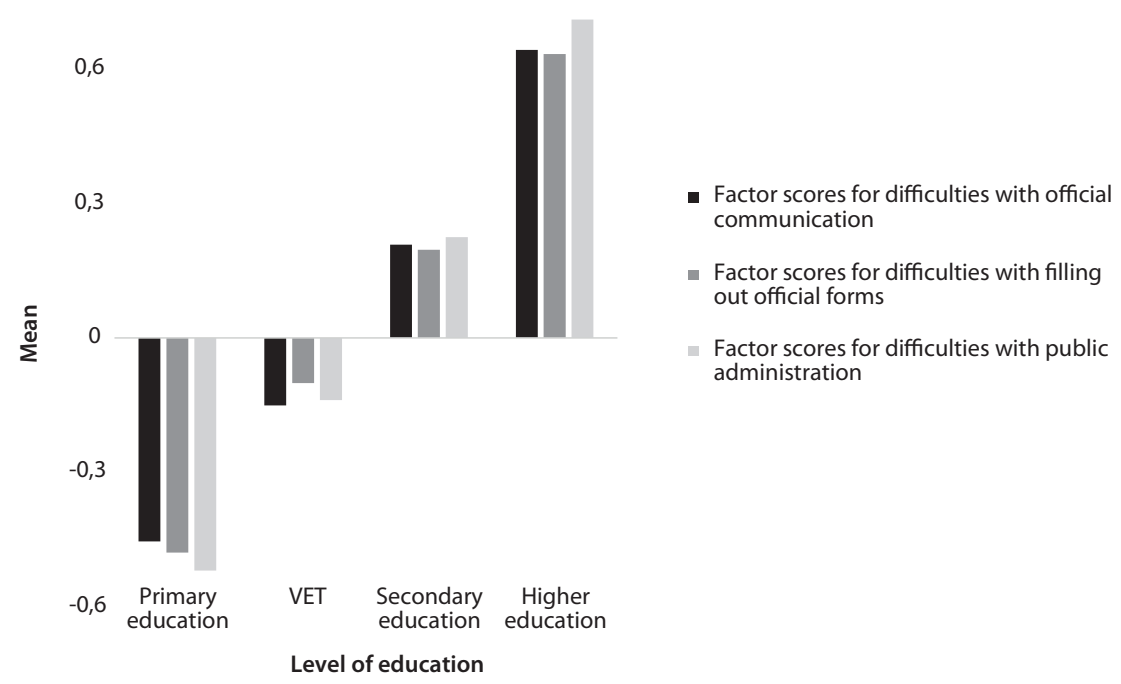

Figure 5 - The difficulties with public administration (communication, managing forms and summarised) between educational groups, $N=2380$ (Source: Good State Public Administration Opinion Survey 2017.)

According to questions (which were selected from items in the questionnaire covering channel-preferences with comparing the different options in pairs, and also the avoidance of certain channels, for example, online, person, post, telephone) on people's channel preferences (Table 2) we can state that 60 per cent of the regular internet user respondents said that they try to avoid e-government services if possible, and 74 per cent of them said that they prefer personal contact to the internet. There are many factors that can contribute to these preferences (the heavy development of one-stop-shop Governmental Windows, the quality and quantity of currently available e-government services, and so on), but we can argue that the knowledge gap also plays a significant role. 
Table 2 Channel preferences of internet users in the sample (Source: Good State Public Administration Opinion Survey 2017.)

\begin{tabular}{|l|c|c|}
\hline & $\begin{array}{c}\text { I try to avoid using online } \\
\text { governmental services if possible } \\
(\mathbf{N}=\mathbf{1 6 6 7})\end{array}$ & $\begin{array}{c}\text { I would rather contact public } \\
\text { administration in person than } \\
\text { on the Internet (N = 1660) }\end{array}$ \\
\hline Entirely true & $36 \%$ & $52 \%$ \\
\hline Mainly true & $24 \%$ & $22 \%$ \\
\hline Mainly not true & $20 \%$ & $16 \%$ \\
\hline Not true at all & $19 \%$ & $10 \%$ \\
\hline
\end{tabular}

As the intensity and variety of internet usage and difficulties with public administration case handling are also highly correlating factors, we could state that on the one hand, one is predicting the other (meaning that e-government is the assumed first choice only for an intensely internet-using fragment of the population with wider knowledge about public administration) and on the other hand, e-government services - in order to gain more attention and usage - need to be not only easy-to-use, but have to provide guidance and hide potential complexity from the user (Figure 5).

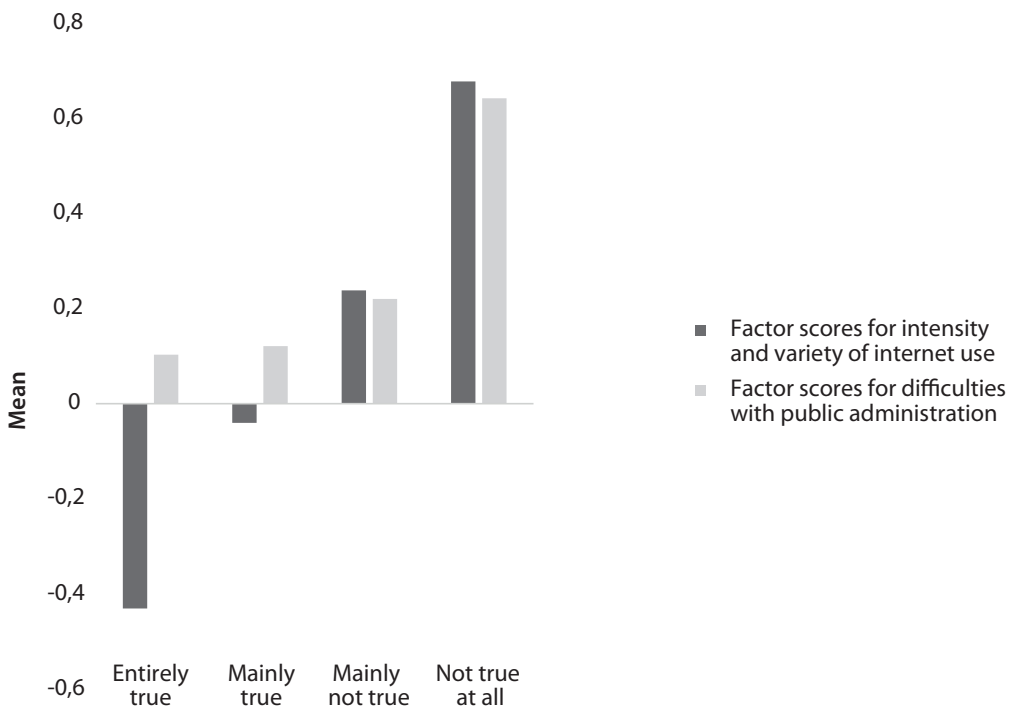

"I try to avoid using online governmental services if possible"

Figure 6 - The avoidance of e-government services and factor scores of internet use and PA knowledge, $N=1603$ (Source: Good State Public Administration Opinion Survey 2017.) 


\section{DISCUSSION - WHAT THE KNOWLEDGE GAP CAN SAY ABOUT E-GOVERNMENT ACCEPTANCE MODELS}

Based on the results of the GSPAOS, it can be concluded that the knowledge gap manifests itself in the citizens' perceived ability to deal with public administration. It highlights that e-government adoption is not only about adopting new technology, but also about dealing with unfamiliar procedures, lack of self-efficacy, and possibly discomfort and anxiety. One of the main characteristics of public administration procedures is their mandatory nature, which can be associated with no tolerance of mistakes (so that a mistake can have significant consequences for the client), thus uncertainty has to be avoided. Facilitating conditions (support to the use of a system) is included in most e-government adoption models (usually in a simplified manner), and they are regarded as a positive influence on e-government adoption, but in some cases it may also result in the opposite: if someone has to ask for support and if support is available, it is much easier (and in the absence of procedural knowledge can also be perceived much more safe) to ask for help to do the transaction rather than asking for help to deal with the online service (particularly in situations where a network of physical customer service centres are available, for example, the Governmental Windows in Hungary).

Earlier experience (and habit) is an important part of the models in almost all cases, but, in most studies, this construct is defined as experience with technology, and, in some research, this construct is rephrased as experience with the internet/computers explicitly. In some rare instances in the literature review, familiarity with procedures, or perceived necessary knowledge, can also serve as a moderator in the adoption process. One of the main results of the GSPAOS survey was that one third of the respondents ( 32.5 per cent) had not been involved in any public administration procedure and people have only dealt with 1.3 cases on average in the last three years before the survey. This demonstrates the fact that e-government services can hardly be 'killer applications' because of their rarity. For many citizens, the regular experience (or routine) with public administration is lacking, and it may also be reflected in different effort expectancy and compatibility constructs, especially if they are phrased in the questionnaires in a way that can mean both technology-related efforts or understandings related to the case. The GAM model partially and implicitly contains this aspect in the perceived information quality construct (information at the website is up-to-date, relevant and easy to understand). Another potential factor in this aspect can be the difference between the online services of public administration and other businesses. They can differ in logic or, as some research concluded, ${ }^{46}$ not live up to the

Forrest V Morgeson and Sunil Mithas, 'Does E-Government Measure Up to E-Business? Comparing End User Perceptions of U.S. Federal Government and E-Business Web Sites', Public Administration Review 69, no 4 (2009), 740-752; Patrice M Mareschal and Joel P Rudin, 'E-Government Versus E-Business: A Comparison of Online Recruitment in the Public and Private Sectors', The American Review of Public Administration 41, no 4 (2011), 453-467. 
state-of-art, as governmental websites tended to be less user-friendly and informative than their private-sector counterparts.

The GAM model concluded that e-government adoption behaviour also changes based on service maturity levels, and as service maturity usually implies growing complexity as well, it may mean that using one general model to describe the e-government adoption factors can result in overly general findings, not detailed enough to justify actions and decisions in order to boost take up of the services. For example, if a case needs authentication or digitally signed documents (where adopting digital signature or any other specific technology might also be needed), then the technological, economic, personal and social perspectives might be notably different. Models ought to be tailored and fine-tuned for a set of services that are comparable in complexity.

Education (as a moderator) has been added to many UTAUT-based or other e-government adoption models, but it could (and because of the strong relationship that proved in many researches and also in GSPAOS data it does) moderate not only the effect of the IT system/ website-related factors, but impact perceived necessary procedural knowledge also, which can change the dynamics among different factors. Age is another widely used moderator in different models, based on the assumption that elderly individuals encounter greater problems when coping with IT systems, but there is, however, a second trend that can be seen from GSPAOS data that is somewhat counterintuitive: middle-aged people (those between the ages 40 and 50) have the most cases with public administration, generating more experience (and possibly insight) with the procedures, which can potentially boost their intention (or self-efficacy and perceived behavioural control) to rely on digital services (or at least reduce their anxiety). The impact may be relatively minor on the model level, but this kind of information can help to identify smaller groups of citizens that may be easier to involve (with the help of small incentives or behavioural insights).

As earlier noted, in order to boost e-government adoption, services need to not just be easy to use or 'state-of-the-art', but hide the potential complexity of the procedures from the user, too (current automation trends provide solutions in case of procedures that can be fully automated). Also, the quality of information services into the models may make a contribution to capture this aspect. Berlilana and Hariguna merged the UTAUT framework with the ISQ model (which is aimed at determining the quality of an information system in order to provide the anticipated results required by the user), and they stated that to achieve e-government that has good qualities, it requires usability and credibility $^{47}$ - in other words, it has to be able to persuade users that they can avoid any unintended consequence in the future.

47 Berlilana, Taqwa Hariguna and Nurfaizah, 'Understanding of Public Behavioral Intent to Use e-Government Service: An Extended of Unified Theory of Acceptance Use of Technology and Information System Quality', Procedia Computer Science 124 (2017), 585-592. 


\section{CONCLUSIONS}

In these times, when a significant amount of public funding is used to develop e-government services (sometimes in parallel with customer service offices and physical one-stopshops), to understand how the knowledge gap (and other factors) affects e-government adoption or channel preferences, it is essential to optimally use resources. Using the representative database from the Good State Public Administration Opinion Survey, the paper showed that a wide knowledge gap exists among Hungarian citizens in terms of public administration-related knowledge and consequently how they can deal with procedures relating to official forms and in communicating their cases. These gaps (together with the discrepancies in internet use) significantly influence the choice of channel for managing administrative issues. In current e-government adoption models, the necessary knowledge about the phenomenon of public administration procedures is marginally incorporated, but this paper argues that it can have a significant effect on adoption, or alter the constructs in these models.

In knowledge gap research, seeing only a given point of time and one issue is only sufficient to say that the gap does or does not exist. Further research is needed in order to compare the knowledge gap over time (widening, stagnating or shrinking) and also to examine not e-government as a whole but rather different cases or groups of cases as they have different publicity and media coverage (for example, the introduction of the widely advertised, proactive Electronic Personal Income Tax Return service in Hungary), and also ought to be tailored and for a set of services that are comparable in complexity. All in all, the knowledge about public administration procedures is an important contributor of e-government adoption and can be used to examine the channel preferences of people that could help to optimise resources in public administration. 


\section{REFERENCES}

1. Aburumman, Nemer and Róbert Szilágyi, 'Factors Affecting Acceptance of Government: Using Extended UTAUT2'. Journal of EcoAgriTourism 16, no 1 (2020), 62-69.

2. Ajzen, Icek, 'From Intentions to Actions: A Theory of Planned Behavior', in Action Control: From Cognition to Behavior, ed. by Julius Kühl and Jürgen Beckmann. BerlinHeidelberg: Springer, 1985. Online: https://doi.org/10.1007/978-3-642-69746-3_2

3. Ajzen, Icek, 'The theory of planned behaviour'. Organizational Behavior and Human Decision Processes 50, no 2 (1991), 179-211. Online: https://doi.org/10.1016/07495978(91)90020-T

4. Al Awadhi, Suha and Anne Morris, 'The Use of the UTAUT Model in the Adoption of E-Government Services in Kuwait', in Proceedings of the 41st Annual Hawaii International Conference on System Sciences (HICSS 2008), 219-219. Online: https:// doi.org/10.1109/HICSS.2008.452

5. Al Mansoori, Khaled Ahmed, Use of a Modified UTAUT Model to Investigate Emirati Citizens' Adoption of e-Government in Abu Dhabi. PhD Thesis, University of Wollogong MBA, Faculty of Business, 2007.

6. Aranyossy, Márta, 'Citizen adoption of e-government services: Evidence from Hungary', in $31^{\text {st }}$ Bled eConference Digital Transformation: Meeting the Challenges: 17-20 June 2018, Bled, Slovenia, Conference Proceedings ed. by Adreja Pucihar, Mirjana Kljajić Borštnar, Pascal Ravesteijn, Jurgen Seitz and Roger Bons. Maribor: University of Maribor Press, 2018, 27-46. Online: https://doi.org/10.18690/978-961-286-170-4.3

7. Bandura, Albert, Social Foundations of Thought and Action: A Social Cognitive Theory. Englewood Cliffs NJ: Prentice-Hall, 1986.

8. Belanche, Daniel, Luis V Casaló and Carlos Flavián, 'Integrating trust and personal values into the Technology Acceptance Model: The case of e-government services adoption'. Cuadernos de Economía y Dirección de la Empresa 15, no 4 (2012), 192-204. Online: https://doi.org/10.1016/j.cede.2012.04.004

9. Berlilana, Taqwa Hariguna and Nurfaizah, 'Understanding of Public Behavioral Intent to Use e-Government Service: An Extended of Unified Theory of Acceptance Use of Technology and Information System Quality'. Procedia Computer Science 124 (2017), 585-592. Online: https://doi.org/10.1016/j.procs.2017.12.193

10. Bonfadelli, Heinz, 'The Internet and Knowledge Gaps: A Theoretical and Empirical Investigation'. European Journal of Communication 17, no 1 (2002), 65-84. Online: https://doi.org/10.1177/0267323102017001607

11. Carifio, James and Rocco J Perla, 'Ten common misunderstandings, misconceptions, persistent myths and urban legends about Likert scales and Likert response formats and their antidotes'. Journal of Social Sciences 3, no 3 (2007), 106-116. Online: http:// dx.doi.org/10.3844/jssp.2007.106.116 
12. Carter, Lemuria and France Belanger, 'The utilization of e-government services: Citizen trust, innovation and acceptance factors'. Information Systems Journal 15, no 1 (2005), 5-25. Online: https://doi.org/10.1111/j.1365-2575.2005.00183.x

13. Davis, Fred D, 'Perceived Usefulness, Perceived Ease of Use, and User Acceptance of Information Technology’. MIS Quarterly 13, no 3 (1989), 319-340. Online: https://doi. org/10.2307/249008

14. Dimitrova, Daniela V and Yu-Che Chen, 'Profiling the Adopters of E-Government Information and Services: The Influence of Psychological Characteristics, Civic Mindedness, and Information Channels'. Social Science Computer Review 24, no 2 (2006), 172-188. Online: https://doi.org/10.1177/0894439305281517

15. Fishbein, Martin and Icek Ajzen, Beliefs, Attitude, Intention and Behavior: An Introduction to Theory and Research. Reading, MA: Addison-Wesley, 1975.

16. Gaziano, Cecilie, 'The knowledge gap: An analytical review of media effects'. Communication Research 10, no 4 (1983), 447-486. Online: https://doi.org/10.1177/ 009365083010004003

17. Gaziano, Cecilie, 'Forecast 2000: Widening knowledge gaps'. Journalism \& Mass Communication Quarterly 74, no 2 (1997), 237-264. Online: https://doi.org/10.1177/ 107769909707400202

18. Gupta, Kriti Priya, Swati Singh and Preeti Bhaskar, 'Citizen adoption of e-government: a literature review and conceptual framework'. Electronic Government, An International Journal 12, no 2 (2012), 160-185. Online: https://doi.org/10.1504/EG.2016.076134

19. Hargittai, Eszter, 'Second-level digital divide: differences in people's online skills'. First Monday 7, no 4 (2002). Online: https://doi.org/10.5210/fm.v7i4.942

20. Hargittai, Eszter and Yuli P Hsieh, 'Digital Inequality', in The Oxford Handbook of Internet Studies, ed. by William H Dutton. Oxford: Oxford University Press, 2013, 129-150. Online: https://www.doi.org/10.1093/oxfordhb/9780199589074.013.0007

21. Hwang, Yoori and Se-Hoon Jeong, 'Revisiting the knowledge gap hypothesis: A metaanalysis of thirty-five years of research'. Journalism \& Mass Communication Quarterly 86, no 3 (2009), 513-532. Online: https://doi.org/10.1177/107769900908600304

22. Kumar, Vinod, Bhasker Mukerji, Irfan Butt and Ajax Persaud, 'Factors for successful e-government adoption: a conceptual framework'. Electronic Journal of E-Government 5, no 1 (2007), 63-76.

23. Larose, Robert, Dana Mastro and Matthew S Eastin, 'Understanding Internet Usage: A social cognitive approach to uses and gratifications'. Social Science Computer Review 19, no 4 (2001), 395-413. Online: https://doi.org/10.1177/089443930101900401

24. Lean, Ooh Kim, Suhaiza Zailani, T Ramayah and Yudi Fernando, 'Factors influencing intention to use e-government services among citizens in Malaysia'. International Journal of Information Management 29, no 6 (2009), 458-475. Online: https:/doi. org/10.1016/j.ijinfomgt.2009.03.012

25. Mareschal, Patrice $M$ and Joel $P$ Rudin, 'E-Government Versus E-Business: A Comparison of Online Recruitment in the Public and Private Sectors'. The American 
Review of Public Administration 41, no 4 (2011), 453-467. Online: https:/doi. org/10.1177/0275074010375573

26. Morgeson, Forrest V and Sunil Mithas, 'Does E-Government Measure Up to E-Business? Comparing End User Perceptions of U.S. Federal Government and E-Business Web Sites'. Public Administration Review 69, no 4 (2009), 740-752. Online: https://doi.org/10.1111/j.1540-6210.2009.02021.x

27. Osmanbegović, Edin and Zijad Lugavić, 'Influencing factors of e-government services adoption in Bosnia and Herzegovina'. Economic Review - Journal of Economics and Business 16, no 2 (2018), 39-51.

28. Rana, Nripendra P, Yogesh K Dwivedi and Michael D Williams, 'Evaluating alternative theoretical models for examining citizen centric adoption of e-government'. Transforming Government: People, Process and Policy 7, no 1 (2013), 27-49. Online: https://doi.org/10.1108/17506161311308151

29. Rogers, Everett M, Diffusion of Innovations. $5^{\text {th }}$ edition. New York: Free Press, 2003.

30. Seo, DongBack and Michel Bernsen, 'Comparing attitudes toward e-government of non-users versus users in a rural and urban municipality'. Government Information Quarterly 33, no 2 (2016), 270-282. Online: https://doi.org/10.1016/j.giq.2016.02.002

31. Shareef, Mahmud Akhter, Vinod Kumar, Uma Kumar and Yogesh Dwivedi, 'E-Government adoption model (GAM): differing service maturity levels'. Government Information Quarterly 28, no 1 (2011), 17-35. Online: https://doi.org/10.1016/j.giq. 2010.05.006

32. Silverstone, Roger and Leslie Haddon, 'Design and the domestication of information and communication technologies: Technical change and everyday life', in Communication by design: The politics of information and communication technologies, ed. by Roger Silverstone and Robin Mansell. Oxford: Oxford University Press, 1996.

33. Suh, Bomil and Ingoo Han, 'The impact of customer trust and perception of security control on the acceptance of electronic commerce'. International Journal of Electronic Commerce 7, no 3 (2003), 135-161. Online: https://doi.org/10.1080/10864415.2003.110 44270

34. Tichenor, Phillip J, George A Donohue and Clarice N Olien, 'Mass media flow and differential growth in knowledge'. Public Opinion Quarterly 34, no 2 (1970), 159-170. Online: https://doi.org/10.1086/267786

35. Van Dijk, Jan AGM, Oscar Peters and Wolfgang Ebbers, 'Explaining the acceptance and use of government Internet services: A multivariate analysis of 2006 survey data in the Netherlands'. Government Information Quarterly 25, no 3 (2008), 379-399. Online: https://doi.org/10.1016/j.giq.2007.09.006

36. Venkatesh, Viswanath, Michael G Morris, Gordon B Davis and Fred D Davis, 'User Acceptance of Information Technology: Toward a Unified View'. MIS Quarterly 27, no 3 (2003), 425-478. Online: https://doi.org/10.2307/30036540

37. Venkatesh, Viswanath, James Y L Thong and Xin Xu, 'Consumer acceptance and use of information technology: extending the unified theory of acceptance and 
use of technology'. MIS Quarterly 36, no 1 (2012), 157-178. Online: https://doi. org/10.2307/41410412

38. Voutinioti, Anastasia, 'Determinants of User Adoption of e-Government Services in Greece and the role of Citizen Service Centres'. Procedia Technology 8 (2013), 238-244. Online: https://doi.org/10.1016/j.protcy.2013.11.033

39. Wang, Yi-Shun, 'The adoption of electronic tax filing systems: an empirical study'. Government Information Quarterly 20, no 4 (2003), 333-352. Online: https://doi.org/ 10.1016/j.giq.2003.08.005

40. Wexler, Natalie, The Knowledge Gap. New York: Avery, 2019.

Mihály Csótó is an agricultural engineer, sociologist, and completed his doctoral studies at the Károly Ihrig Doctoral School of Management and Business, University of Debrecen in 2016. Currently, he is the Managing Director of Chelonian Bt. He had worked for the Information Society and Trend Research Institute (Budapest University of Technology and Economics) for more than 10 years, his main topics were e-government, digital divide and e-agriculture. He served at the Ministry of Public Administration and Justice as an e-government expert (2013-2014). More recently he worked for the University of Public Service (Institute for Research and Development on State and Governance, later Institute for Public Administration Further Training), where he was mainly involved in the evaluation of national public administration development/digitisation projects (2017-2020). He is one of the editors (and former editor-in-chief) of the Hungarian scientific quarterly Információs Társadalom, and also a board member of the Hungarian Association of Agriculture Informatics. 